\title{
Is jugular bulb oximetry monitoring associated with outcome in out of hospital cardiac arrest patients?
}

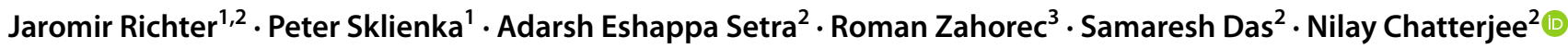

Received: 29 October 2019 / Accepted: 13 May 2020 / Published online: 20 May 2020

(c) The Author(s) 2020

\begin{abstract}
Cerebral protection against secondary hypoxic-ischemic brain injury is a key priority area in post-resuscitation intensive care management in survivors of cardiac arrest. Nevertheless, the current understanding of the incidence, diagnosis and its' impact on neurological outcome remains undetermined. The aim of this study was to evaluate jugular bulb oximetry as a potential monitoring modality to detect the incidences of desaturation episodes during post-cardiac arrest intensive care management and to evaluate their subsequent impact on neurological outcome. We conducted a prospective, observational study in unconscious adult patients admitted to the intensive care unit who had successful resuscitation following out of hospital cardiac arrest of presumed cardiac causes. All the patients were treated as per European Resuscitation Council 2015 guidelines and they received jugular bulb catheter. Jugular bulb oximetry measurements were performed at six hourly intervals. The neurological outcomes were evaluated on 90th day after the cardiac arrest by cerebral performance categories scale. Forty patients met the eligibility criteria. Measurements of jugular venous oxygen saturation were performed for 438 times. Altogether, we found 2 incidences of jugular bulb oxygen saturation less than 50\% (2/438;0.46\%), and 4 incidences when it was less than $55 \%(4 / 438 ; 0.91 \%)$. The study detected an association between $\mathrm{SjVO}_{2}$ and $\mathrm{CO}_{2}(\mathrm{r}=0.26)$, each $1 \mathrm{kPa}$ increase in $\mathrm{CO}_{2}$ led to an increase in $\mathrm{SjvO}_{2}$ by $3.4 \%+/-0.67(\mathrm{p}<0.0001)$. There was no association between $\mathrm{SjvO}_{2}$ and $\mathrm{PaO}_{2}$ or $\mathrm{SjvO}_{2}$ and MAP. We observed a statistically significant higher mean $\mathrm{SjvO}_{2}(8.82 \%+/-2.05, \mathrm{p}<0.0001)$ in unfavorable outcome group. The episodes of brain hypoxia detected by jugular bulb oxygen saturation were rare during post-resuscitation intensive care management in out of hospital cardiac arrest patients. Therefore, this modality of monitoring may not yield any additional information towards prevention of secondary hypoxic ischemic brain injury in post cardiac arrest survivors. Other factors contributing towards high jugular venous saturation needs to be considered.
\end{abstract}

Keywords Brain hypoxia $\cdot$ Jugular bulb oxygen saturation $\cdot$ Out of hospital cardiac arrest $\cdot$ Cerebral edema $\cdot$ Monitoring

\section{Introduction}

Annually, about 1 in 1000 people experience out of hospital cardiac arrest (OHCA), of which about $25 \%$ survive to hospital admission and only $10 \%$ survive until hospital discharge

Jaromir Richter

jaromir.richter.69@gmail.com

Peter Sklienka

peter.sklienka@seznam.cz

Adarsh Eshappa Setra

adarshshettar@yahoo.co.in

Roman Zahorec

roman.zahorec@ousa.sk

Samaresh Das

drsamareshdas@gmail.com
[1]. The most common cause of death in OHCA patients who survive to intensive care unit (ICU) admission is severe neurological injury which is a summation of primary and secondary hypoxic ischemic brain injuries, HIBI $[2,3]$. The primary HIBI is caused by cessation of cerebral blood flow during the

Nilay Chatterjee

nilay.chatt@gmail.com

1 Department of Anesthesiology and Intensive Care Medicine, University Hospital Ostrava, Ostrava, Czech Republic

2 Department of Anaesthetics, Yeovil Hospital, Greater Kingston, Somerset BA21 4AT, UK

3 Second Department of Anesthesiology and Intensive Medicine, Medical School, Comenius University, Bratislava, Slovak Republic 
cardiac arrest and it resumes with the return of spontaneous circulation (ROSC). Subsequently there is a period characterized by an imbalance between cerebral oxygen demand and cerebral oxygen delivery which may occur within minutes, hours or days after ROSC. This results in secondary HIBI. The cerebral protection strategies against secondary HIBI remains the key priority of post-cardiac arrest (post-CA) ICU management.

There is a paucity of information regarding the incidence of cerebral hypoxia following OHCA in medical literature. Nevertheless, no ideal method for bedside monitoring of cerebral oxygenation has been identified. Commonly employed methods for cerebral oxygenation are: (i) jugular bulb oxygen saturation $\left(\mathrm{SjvO}_{2}\right)$, (ii) brain tissue oxygen tension $\left(\mathrm{PbtO}_{2}\right)$, and (iii) near-infrared spectroscopy, NIRS [4]. $\mathrm{SjvO}_{2}$ monitoring is a relatively simple method, which measures the oxygen saturation of the blood returning from cerebral circulation via a catheter inserted retrograde into the internal jugular vein and advanced into the jugular bulb. It can be continuous or intermittent process which reflects the global balance between cerebral oxygen supply and consumption according to the Fick principle. $\mathrm{SjvO}_{2}$ has been used extensively in patients with severe traumatic brain injury (TBI). Brain Trauma Foundation (BTF) 2016 guidelines for management of severe TBI mentions only $\mathrm{SjvO}_{2}$ (level III recommendations) as advanced cerebral monitoring for detecting cerebral hypoxia $\left(\mathrm{SjvO}_{2}<50 \%\right.$ is considered as threshold) [5]. Brain tissue oxygen tension monitoring $\left(\mathrm{PbtO}_{2}\right)$ involves direct estimation of regional brain tissue oxygen tension by introducing a small catheter into the brain parenchyma. The prime disadvantage of this method is its invasiveness. NIRS has been considered to be a promising method for non-invasively assessing cerebral oxygenation. The changes in cerebral oxygenation derived from NIRS might reflect the changes in relationship between oxygen delivery and consumption in the brain [6]. However, some of the recent studies conducted in brain-dead patients demonstrated that NIRS is more likely to be affected by extracranial perfusion status rather than truly reflecting intracranial perfusion $[7,8]$. Because of this presently NIRS may not be considered to be an ideal routine monitoring device for cerebral oxygenation [9].

The aims of the present study were (i) to evaluate $\mathrm{SjvO}_{2}$ as a possible monitoring modality for detecting desaturation episodes during post-CA ICU care and (ii) assessing the impact of secondary HIBI (arising during desaturation episodes of $\mathrm{SjvO}_{2}$ ) on neurological outcome of the patients.

\section{Materials and methods}

\subsection{Study design}

This prospective, observational, single centre study was performed from July 2016 to September 2018 in a tertiary care
ICU (admitting mixed medical/surgical patient population) in University Hospital Ostrava, Czech Republic. The clinicians were blinded to the $\mathrm{SjvO}_{2}$ results. The study protocol and informed consent procedures were approved by Local Medical Ethics Committee (Ethics Committee of FN Ostrava Ref No. 410/2016). Because of patients' clinical state it was not feasible to obtain informed consent at the time of intervention. Therefore, a deferred informed consent from the patient's next of kin was obtained as soon as possible. In addition, we obtained informed consent from all the patients who regained sufficient neurological function (Cerebral Performance Category CPC 1-2). The study was registered with ClinicalTrials.gov (Identifier NCT02806778).

\subsection{Patients}

We consecutively screened all unconscious adult patients who were admitted to the ICU following OHCA between July 2016 and September 2018. The inclusion criteria were (i) age $>18$ years, (ii) all patients who had OHCA of presumable cardiac cause, (iii) Glasgow Coma Scale (GCS) $</=8$ following ROSC and unable to follow verbal commands. The exclusion criteria were (i) pregnancy, (ii) OHCA secondary to any non-cardiac cause, (iii) severe comorbid conditions resulting in limited life expectancy, (iv) confirmed acute intracranial bleeding, (v) greater than $6 \mathrm{~h}$ (360 min) of duration between the time of cardiac arrest and the time of first jugular bulb blood sampling, and (vi) patients who died within $72 \mathrm{~h}$ from cardiac arrest due to refractory postCA shock.

\subsection{Management protocol}

All the patients admitted to the study received out-of-hospital advanced life support performed by an emergency team, which included a physician trained in emergency medicine. Patients who had successful ROSC were transported to the Emergency Department at our Tertiary Care Centre. Patients with a presumed cardiac origin of OHCA were immediately taken to the catheterization laboratory for a coronary angiogram (followed by a percutaneous coronary intervention, if indicated) according to the decision made by a consultant cardiologist. When the cardiac cause of OHCA was not confirmed, a head and chest computed tomography (CT) scan were performed to evaluate neurological or respiratory etiology.

Thereafter, patients were admitted to the ICU for post-resuscitation care according to European Resuscitation Council (ERC) guidelines $\left(\mathrm{SaO}_{2} 94-98 \%, \mathrm{PaCO}_{2}\right.$ 4.6-6.0 kPa; optimal mean arterial pressure (MAP) to achieve adequate urine output and normal or decreasing trend of plasma lactates, adequate sedation and early diagnosis/treatment of seizure) [10]. Following the institutional 
protocol the core temperature of all the patients were maintained between 35 and $36{ }^{\circ} \mathrm{C}$ for $24 \mathrm{~h}$ using external surface cooling technique. Patients were sedated with sufentanyl, propofol and/or midazolam. The aim of sedation during the targeted temperature management (TTM) was to achieve Richmond agitation sedation score (RASS) within the range of -4 to -5 and to eliminate clinical seizures and shivering [11]. The arterial and central venous catheters were inserted in all the patients. In addition, a single lumen catheter was inserted retrograde into the ultrasonographically determined dominant jugular vein or in the right jugular vein [12]. The final position of the tip of the catheter was confirmed above the lower border of the $\mathrm{C} 1$ vertebra, as confirmed on a lateral cervical spine X-ray [13]. Blood samples were drawn gently through the jugular vein catheter for $\mathrm{SjvO}_{2}$ sampling to prevent any retrograde admixture.

\subsection{Data collection and interpretation}

The first blood sample for $\mathrm{SjvO}_{2}$ was drawn from the jugular bulb catheter immediately following ICU admission and jugular bulb cannulation (time $\mathrm{T}_{0}$ ). Then serial samples were taken at every $6 \mathrm{~h}$ until $72 \mathrm{~h}$ post-CA (time $\mathrm{T}_{66}$ ) or until the time of extubation. According to the study protocol, jugular bulb blood samples were blinded to the laboratory and the treating physician was unaware about the $\mathrm{SjvO}_{2}$ results. Thus, no diagnostic or therapeutic interventions were performed based on $\mathrm{SjvO}_{2}$ values. Arterial blood samples were taken simultaneously with jugular bulb samples, and MAP values were recorded at each of these points of time.

\subsection{Outcome assessment}

The primary outcome was the incidence of secondary HIBI, as detected by the jugular bulb oximetry. Brain hypoxia was considered as $\mathrm{SjvO}_{2}<50 \%$ according to BTF 2016 guidelines [5]. The secondary outcome was to determine any association between the incidences of secondary HIBI and the neurological outcomes in this population. Patients were evaluated by a consultant neurologist 90 days after their cardiac arrest. CPC 1 and 2 were considered as a favorable outcome, whereas CPC 3, 4 and 5 were considered as a unfavorable outcome [14].

\subsection{Statistics}

The data obtained from the study was expressed in the tabular form (Tables 1, 2, 3). The normality of the numeric variables was tested using the Shapiro-Wilk test and a logarithmic transformation was applied in order to normalize the skewed data when required. Numerical data were expressed as mean $+/-$ standard deviation (SD) or median and $25-75 \%$ inter-quantile range. The numerical variables between the groups were compared using paired t-test or Wilcoxon rank sum test. The categorical variables were compared with chi square test or Fisher's exact test, as applicable. A linear mixed model was used to demonstrate the correlations between $\mathrm{SjvO}_{2}$ and $\mathrm{MAP}, \mathrm{PaCO}_{2}, \mathrm{PaO}_{2}$. A p value $<0.05$ was considered to be statistically significant. $\mathrm{R}$ statistical software version 3.5.2 (R Core Team 2019) was used for the analysis.

Table 1 Study variables

\begin{tabular}{|c|c|c|c|c|}
\hline Variables & Favorable outcome & Unfavorable outcome & Total & $\mathrm{p}$ \\
\hline Number of patients & 17 & 23 & 40 & \\
\hline Gender ( $\%$ of male) & $15 / 17(88)$ & $21 / 23(91)$ & $36 / 40(90)$ & NS \\
\hline Age (years) $($ mean $+/-\mathrm{SD})$ & $55.47+/-10.84$ & $61.39+/-9.66$ & $58.88+/-10.47$ & NS \\
\hline Time of arrest to ROSC (min) (mean $+/-\mathrm{IQR})$ & $14 / 17(8-25)$ & $21 / 23(18-33)$ & $20.5(14-29.3)$ & 0.012 \\
\hline \multicolumn{5}{|l|}{ Initial rhythm } \\
\hline Asystole/PEA (\%) & $0 / 17(0)$ & $7 / 23(30)$ & $7 / 40(18)$ & 0.014 \\
\hline Shockable rhythm (\%) & $17 / 17(100)$ & $16 / 23(70)$ & $33 / 40(82)$ & 0.014 \\
\hline APACHE II (mean +/-IQR) & $25(23.5-27)$ & $29(26.5-33)$ & $28(25-30)$ & 0.014 \\
\hline \multicolumn{5}{|l|}{ Initial tests } \\
\hline Hemoglobin $(\mathrm{g} / \mathrm{dl})($ mean $+/-\mathrm{SD})$ & $14.4+/-1.7$ & $14.1+/-1.6$ & $14.2+/-1.6$ & NS \\
\hline $\mathrm{pH}($ mean $+/-\mathrm{SD})$ & $7.27(7.25-7.33)$ & $7.27(7.11-7.37)$ & $7.27(7.18-7.36)$ & NS \\
\hline Lactate $(\mathrm{mmol} / \mathrm{l})($ mean $+/-\mathrm{IQR})$ & $1.9(1.3-3.9)$ & $2.2(1.65-6.15)$ & $2.1(1.3-5.72)$ & NS \\
\hline Underwent coronary angiography (\%) & $16 / 17(94)$ & $22 / 23(96)$ & $38 / 40(95)$ & NS \\
\hline Underwent $\mathrm{PCI}+$ coronary angiography $(\%)$ & $10 / 17(59)$ & $13 / 23(57)$ & $23 / 40(58)$ & NS \\
\hline
\end{tabular}

$S D$ standard deviation, $I Q R 25-75 \%$ inter quartile range 
Table $2 \mathrm{SjvO}_{2}$ levels at different time intervals and outcomes

\begin{tabular}{lccl}
\hline $\mathrm{SjvO}_{2}$ values & $\begin{array}{l}\text { Favorable outcome } \\
\text { (mean+/-IQR) }\end{array}$ & $\begin{array}{l}\text { Unfavora- } \\
\text { ble outcome } \\
\text { (mean+/-IQR) }\end{array}$ & $\mathrm{p}$ \\
\hline $\mathrm{T}_{0}$ & $75(68-79)$ & $75(63.5-78.5)$ & $\mathrm{NS}$ \\
$\mathrm{T}_{6}$ & $77(72-80)$ & $79(69.5-82)$ & $\mathrm{NS}$ \\
$\mathrm{T}_{12}$ & $75(72-83)$ & $81(77-86)$ & $\mathrm{NS}$ \\
$\mathrm{T}_{18}$ & $74.5(68.5-78.25)$ & $83(79-87.5)$ & 0.0003 \\
$\mathrm{~T}_{24}$ & $76(71-80)$ & $84(78-87.5)$ & 0.004 \\
$\mathrm{~T}_{30}$ & $78(71-81)$ & $83(77-85.5)$ & 0.01 \\
$\mathrm{~T}_{36}$ & $75(62.5-79)$ & $82(76-86.5)$ & 0.007 \\
$\mathrm{~T}_{42}$ & $71(64.25-78.75)$ & $81(78.25-84.75)$ & 0.0006 \\
$\mathrm{~T}_{48}$ & $77(66-78)$ & $82.5(80-85)$ & 0.002 \\
$\mathrm{~T}_{54}$ & $70(68-77)$ & $82(81-86)$ & $<0.0001$ \\
$\mathrm{~T}_{60}$ & $72(67.5-76)$ & $83(79.25-86.5)$ & 0.003 \\
$\mathrm{~T}_{66}$ & $71(67.25-74.25)$ & $81.5(79.25-85.75)$ & 0.0004 \\
\hline
\end{tabular}

\section{Results}

From July 2016 until September 2018, 54 consecutive OHCA patients of cardiac origin were presented to our Tertiary Care Center. Fourteen of them were excluded, as they did not meet the inclusion criteria (8 died within $72 \mathrm{~h}$ due to refractory post CA shock, 3 were found to have a non-cardiac cause of CA, 1 had intracranial bleeding after sustaining a fall following OHCA, in 1 patient jugular bulb catheter could not be inserted, 1 had accidental removal of the jugular bulb catheter during $\mathrm{X}$ ray).

Therefore, 40 patients were included in the final analysis. The demographic profile of the patients and the study variables are presented in Table 1. 17 Patients (43\%) survived with a CPC 1 or 2 on day 90 post-CA. The median duration from the time of the cardiac arrest to the time of taking the first blood sample from the jugular bulb catheter was $250 \mathrm{~min}$.

$\mathrm{SjvO}_{2}$ values were measured at every $6 \mathrm{~h}\left(\mathrm{~T}_{0}\right.$ to $\mathrm{T}_{66}$ or until extubated) (Table 2). Altogether $\mathrm{SjvO}_{2}$ measurements were performed 438 times (Table 3 ). $\mathrm{SjvO}_{2}$ values of less than $50 \%$ were detected twice $(2 / 438 ; 0.46 \%)$ in 2 different patients (1 had favorable and the other had unfavorable outcome); whereas $\mathrm{SjvO}_{2}$ values of less than $55 \%$ were detected 4 times $(4 / 438 ; 0.91 \%)$ in 3 different patients ( 2 had favorable and 1 had unfavorable outcome) (Table 3).

More frequent incidence of low $\mathrm{SjvO}_{2}$ was detected in the group of patients who died within $72 \mathrm{~h}$ of ICU admission due to post-CA shock and were excluded from the statistics. This subgroup consisted of 8 patients out of them 7 died within the first $24 \mathrm{~h}$ from cardiac arrest. The mean from the time of ICU admission to death was $11 \mathrm{~h}$. Six of them had two $\mathrm{SjvO}_{2}$ samples drawn and 1 patient had only $1 \mathrm{SjvO}_{2}$ sample. $\mathrm{SjvO}_{2}<50 \%$ was detected three times $(3 / 13,23 \%)$ and each time it was found in the last drawn sample, taken before they died.

Significantly higher mean $\mathrm{SjvO}_{2}$ values were detected in unfavorable outcome group from time $\mathrm{T}_{18}$ until the end of measurement time (Table 2; Fig. 1). No significant difference was found in $\mathrm{PaCO}_{2}$ values between the groups with favorable or unfavorable outcomes. MAP was comparable between the groups at all time points except at $\mathrm{T}_{18}$ (mean 92; range 82.7 to 95.7 and mean 83 ; range 80.5 to 88 in favorable and unfavorable groups respectively, $\mathrm{p}=0.028$ ) and at $\mathrm{T}_{30}$ (mean 82.5 ; range 79.5 to 85 and mean 91 ; range 83 to 97 in favorable and unfavorable groups respectively, $\mathrm{p}=0.025)$ (Fig. 2).

A linear mixed model used to assess the correlation of $\mathrm{SjvO}_{2}$ with $\mathrm{CO}_{2}, \mathrm{MAP}$ and $\mathrm{PaO}_{2}$. The unfavorable outcome group was having a statistically significant higher mean $\mathrm{SjvO}_{2}(8.82 \%+/-2.05, \mathrm{p}<0.0001)$ compared to the
Table 3 Incidence of $\mathrm{SjvO}_{2}<50 \%$ and $<55 \%$ and relation with outcomes

\begin{tabular}{lllc}
\hline $\mathrm{SjvO}_{2}$ & $\begin{array}{l}\text { Favorable outcome } \\
(\mathrm{n}=17)\end{array}$ & $\begin{array}{l}\text { Unfavorable outcome } \\
(\mathrm{n}=23)\end{array}$ & Overall $(\mathrm{n}=40)$ \\
\hline $\mathrm{SjvO}_{2}$ (no of measurements) & $170(39 \%)$ & $268(61 \%)$ & $438(100 \%)$ \\
$\mathrm{SjvO}_{2}<50 \%$ (number of episodes) & 1 & 1 & $2(0.46 \%)$ \\
$\mathrm{SjvO}_{2}<55 \%$ (number of episodes) & 3 & 1 & $4(0.91 \%)$ \\
\hline
\end{tabular}

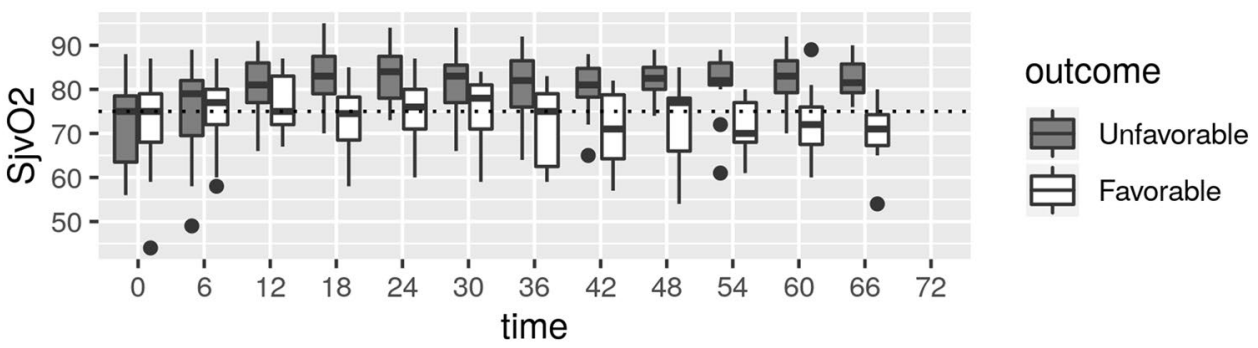


favorable group. An association was found between $\mathrm{SjvO}_{2}$ and $\mathrm{CO}_{2}(\mathrm{r}=0.26)$, each $1 \mathrm{kPa}$ increase in $\mathrm{CO}_{2}$ led to an increase in $\mathrm{SjvO}_{2}$ by $3.4 \%+/-0.67$ (p<0.0001) (Fig. 3). No similar associations were found between $\mathrm{SjvO}_{2}$ and $\mathrm{PaO}_{2}$ $(\mathrm{r}=0.19)$ or $\mathrm{SjvO}_{2}$ and MAP $(\mathrm{r}=0.02)$.

The second aim (impact on neurological outcome) could not be assessed due to very low incidence of desaturation episodes.

\section{Discussion}

Secondary HIBI is considered to be an important factor for adverse outcomes in patients suffering from CA, but there is paucity of information about the precise incidences of brain hypoxic events and which modality is best to detect it. The present study describes the incidences of cerebral hypoxia as detected by jugular bulb oximetry in post-OHCA population. Most of the existing clinical experiences concerning this method is in patients with severe TBI. Previous studies demonstrated associations between secondary brain hypoxia detected by jugular bulb oximetry during ICU care and mortality in victims of TBI $[15,16]$. BTF recommends jugular bulb monitoring of arteriovenous oxygen content difference, as a source of information for management decisions in severe TBI patients (advanced cerebral monitoring, level III recommendations); with a threshold of $\mathrm{SjvO}_{2}$ of less than $50 \%$ in order to reduce mortality and improve outcome [5]. Because of the paucity of guidelines and thresholds of
$\mathrm{SjvO}_{2}$ in post-CA patients we extrapolated cut off point of $\mathrm{SjvO}_{2}$ from TBI [5].

The most significant finding from the study was an extremely low incidence of desaturation episodes $\left(\mathrm{SjvO}_{2}<50 \%\right.$ in $0.46 \%$ of the patients). Even considering a more conservative $\mathrm{SjvO}_{2}$ threshold (i.e. $\mathrm{SjvO}_{2}<55 \%$ ) following an extensive literature search $[17,18]$, could not yield any remarkable difference on the findings $(0.91 \%)$.

Wallin et al. had conducted a prospective study over in 75 adult post-CA comatose patients who had successful ROSC. $49 \%$ of their patients had survived with good neurological outcome at 6 months post-CA, but there was no significant difference in $\mathrm{SjvO}_{2}$ between the patients of good and poor outcome [19]. However, their study included a case mix of OHCA and in hospital CA patients recruited between 2004 and 2012, before the publication of ERC 2015 guidelines. In a recent study with 10 patients of post-CA with a risk of brain injury by Sekhon and colleagues; none of the patients had $\mathrm{SjvO}_{2}$ less than $50 \%$ but $38 \%$ of the times they experienced a brain tissue oxygen below $20 \%$ (by simultaneously monitoring $\mathrm{PbtO}_{2}$ ) [20]. Another interesting results from the study was the association between $\mathrm{SjvO}_{2}$ and $\mathrm{CO}_{2}(\mathrm{r}=0.26)$ (Fig. 3), but no similar associations were found between $\mathrm{SjvO}_{2}$ and $\mathrm{PaO}_{2}(\mathrm{r}=0.19)$ or $\mathrm{SjvO}_{2}$ and MAP $(\mathrm{r}=0.02)$.

There could be several explanations for the low incidences of cerebral desaturation episodes. Post-resuscitation ICU care has greatly improved in recent times. Some studies suggested that by implementing strict therapeutic protocols focused on optimum hemodynamics and TTM in post-CA
Fig. 2 MAP levels at different time intervals in favorable and unfavorable groups
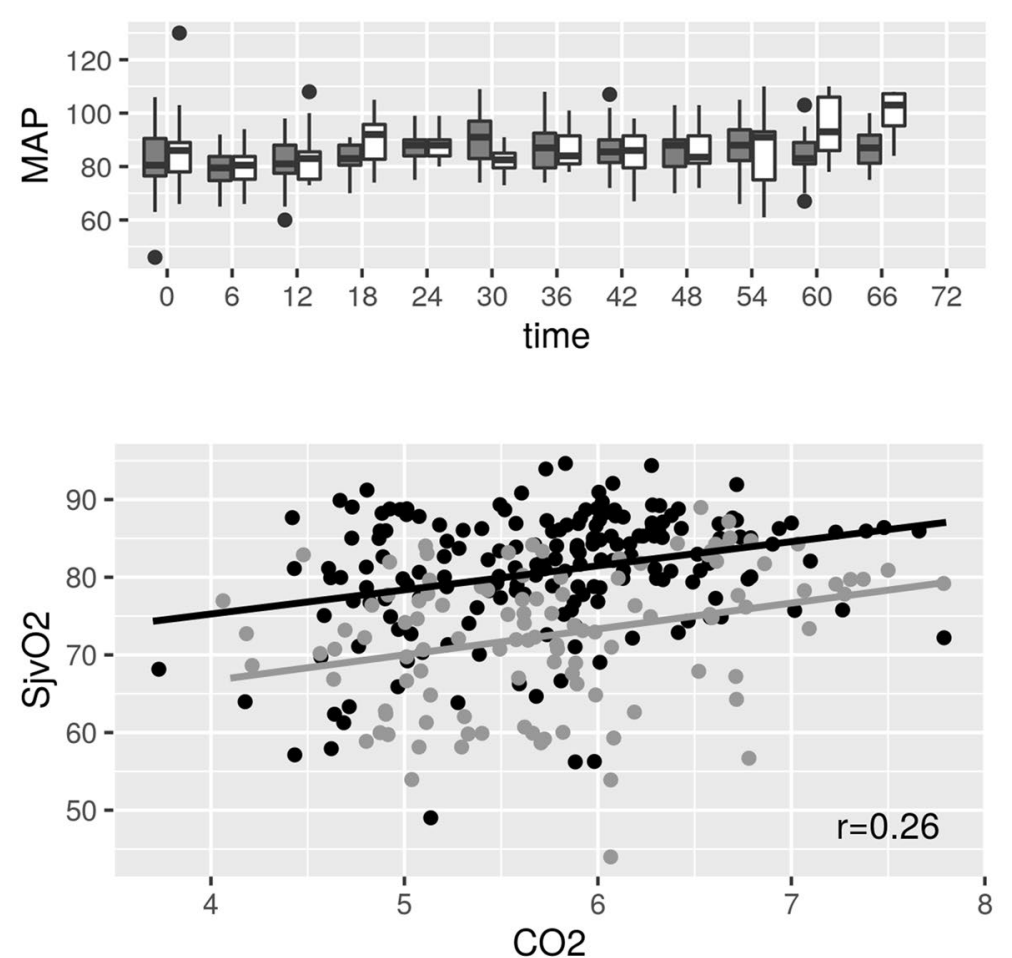

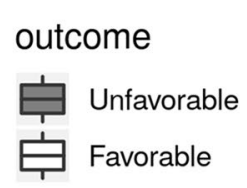

outcome

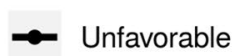

- Favorable
Fig. 3 Correlation between $\mathrm{SjvO}_{2}$ and $\mathrm{PaCO}_{2}$ 
care resulted in improved survival [21, 22]. Implementation of deep sedation regimen could be another potential reason. The existing guidelines recommend for adequate sedation during TTM. There could be considerable variation in sedation protocols amongst individual ICUs [23]. Deep sedations can reduce cerebral oxygen consumption up to $60 \%$ compared to baseline in a dose dependent manner [24-27]. It also suppresses convulsive/nonconvulsive seizures and prevent shivering $[10,28]$. Sedation was aimed for a RASS between -4 and -5 in the present study, however only RASS of -5 was recorded at all times during TTM. There were no episodes of convulsive seizures or shivering in our cohort. Deep sedation might have a potential for cerebral protection [29].

Increased diffusion barriers secondary to cerebral edema may play an important role. Cerebral edema can occur following CA and its extent as evidenced by CT or magnetic resonance imaging (MRI) may be used as prognosticator of neurological outcome. It can manifest as early as $1 \mathrm{~h}$ following successful resuscitation [30] and subsequently worsens in patients with unfavorable outcome [31, 32]. It is probable that hemodynamic optimization provides adequate oxygen delivery to the cerebral microcirculation, but formation of cerebral edema may reduce oxygen diffusion out of the microcirculation, thus $\mathrm{SjvO}_{2}$ can remain 'arterialized' [33]. This could be the reason for discrepancies between $\mathrm{SjvO}_{2}$ and $\mathrm{PbtO}_{2}$ measurements in the study by Sekhon et al. [20]. The present study findings also support this hypothesis. Patients in both the groups (favorable and unfavorable) initially had similar $\mathrm{SjvO}_{2}$ values, but at time $\mathrm{T}_{18}$ onwards $\mathrm{SjvO}_{2}$ values were significantly higher in patients with unfavorable neurological outcome. Other studies have also shown similar trends in $\mathrm{SjvO}_{2}$ [34, 35]. Therefore, in future, it seems logical to consider the means of reducing cerebral edema as the principal therapeutic goal for neuroprotection and subsequently a better neurological outcome in post-CA patients [36].

The initial systemic lactate levels were remarkably low in our cohort. That might have been due to the fact that samples were not taken immediately on arrival to the hospital but collected only after ICU admission. By this time majority of the patients had percutaneous coronary intervention which might have resulted in better systemic perfusion. Moreover, patients with refractory post-CA circulatory failure were expected to have higher mean lactate levels, died within first $72 \mathrm{~h}$. Hence they were excluded from the statistical analysis according to the study protocol.

Our study has few important limitations. Firstly, it is a single centre study with relatively small number of patients. Secondly, jugular bulb oximetry was performed intermittently and frequency of $\mathrm{SjvO}_{2}$ sampling was low. Therefore, there is a theoretical probability that some of secondary hypoxic episodes could have been missed. The possibility of existence of regional brain ischemia could not be excluded as $\mathrm{SjvO}_{2}$ reflects global cerebral oxygenation. Regional cerebral ischemia (focal) could occur in spite of normal $\mathrm{SjvO}_{2}$ values [37]. Finally, this study did not show significant number of episodes brain hypoxia exclusively using $\mathrm{SjvO}_{2}$ as a monitoring modality, the lack of simultaneous use of other intracranial monitoring (e.g. ICP and/or $\mathrm{PbtO}_{2}$ ) is a limitation.

The present study could detect very limited incidences of cerebral desaturation episodes using jugular bulb oximetry. The cause for this could me multifactorial. A statistical correlation with the neurological outcome cannot be computed as the incidences of low $\mathrm{SjvO}_{2}$ were rather rare. The findings from the present study can be further validated by a prospective multicentre study involving larger number of patients with adequate statistical power and using continuous jugular oximetry monitoring. Such study could also potentially include intracranial monitoring thus obtaining correlations between intracranial and $\mathrm{SjvO}_{2}$ values. Further research on this subject should probably focus on post-resuscitation brain edema as one of the potential therapeutic targets.

Acknowledgements Faculty and supporting staff in the Department of Anaesthesiology and Intensive Care Medicine, University Hospital Ostrava, Czech Republic (Fakultní nemocnice Ostrava, 17. listopadu 1790, 70852 Ostrava-Poruba).

Funding Supported by the Ministry of Health, Czech Republic: Conceptual Development of Research Organization (FNOs/2016).

\section{Compliance with ethical standards}

Conflict of interest Authors declare no conflict of interest.

Ethical Approval The trial was approved by the Ethics Committee of University Hospital Ostrava (Ref No. 410/2016) and was registered on the ClinicalTrials registry (NCT02806778. http://clinicaltrials.gov).

Informed consent Informed consent was obtained from next of kin of all individual patients included in this study.

Open Access This article is licensed under a Creative Commons Attribution 4.0 International License, which permits use, sharing, adaptation, distribution and reproduction in any medium or format, as long as you give appropriate credit to the original author(s) and the source, provide a link to the Creative Commons licence, and indicate if changes were made. The images or other third party material in this article are included in the article's Creative Commons licence, unless indicated otherwise in a credit line to the material. If material is not included in the article's Creative Commons licence and your intended use is not permitted by statutory regulation or exceeds the permitted use, you will need to obtain permission directly from the copyright holder. To view a copy of this licence, visit http://creativecommons.org/licenses/by/4.0/. 


\section{References}

1. Gräsner JT, Lefering R, Koster RW, Masterson S, Böttiger BW, et al. EuReCa ONE Collaborators. EuReCa ONE-27 Nations, ONE Europe, ONE Registry: a prospective one month analysis of out-of-hospital cardiac arrest outcomes in 27 countries in Europe. Resuscitation. 2016;105:188-95. https://doi.org/10.1016/j.resus citation.2016.06.004.

2. Lemiale V, Dumas F, Mongardon N, et al. Intensive care unit mortality after cardiac arrest: the relative contribution of shock and brain injury in a large cohort. Intensive Care Med. 2013;39(11):1972-80. https://doi.org/10.1007/s0013 4-013-3043-4.

3. Sekhon MS, Ainslie PN, Griesdale DE. Clinical pathophysiology of hypoxic ischemic brain injury after cardiac arrest: a "two-hit" model. Crit Care. 2017;21(1):90. https://doi.org/10.1186/s1305 4-017-1670-9.

4. Elwishi M, Dinsmore J. Monitoring the brain. BJA Educ. 2019;19(2):54-9. https://doi.org/10.1016/j.bjae.2018.12.001.

5. Carney N, Totten AM, O'Reilly C, Ullman JS, Hawryluk GW, et al. Guidelines for the management of severe traumatic brain injury, fourth edition. Neurosurgery. 2017;80(1):6-15. https://doi. org/10.1227/NEU.0000000000001432.

6. Schnaubelt S, Sulzgruber P, Menger J, et al. Regional cerebral oxygen saturation during cardiopulmonary resuscitation as a predictor of return of spontaneous circulation and favourable neurological outcome- a review of the current literature. Resuscitation. 2018;125:39-47. https://doi.org/10.1016/j.resuscitat ion.2018.01.028.

7. Caccioppola $\mathrm{A}$, Carbonara $\mathrm{M}, \mathrm{Macrì} \mathrm{M}$, et al. Ultrasound-tagged near-infrared spectroscopy does not disclose absent cerebral circulation in brain-dead adults. Br J Anaesth. 2018;121(3):588-94. https://doi.org/10.1016/j.bja.2018.04.038.

8. Cardim D, Griesdale DE. Near-infrared spectroscopy: unfulfilled promises. Br J Anaesth. 2018;121(3):523-6. https://doi. org/10.1016/j.bja.2018.05.058.

9. Sandroni C, Parnia S, Nolan JP. Cerebral oximetry in cardiac arrest: a potential role but with limitations. Intensive Care Med. 2019;45(6):904-6. https://doi.org/10.1007/s00134-019-05572-7.

10. Nolan JP, Soar J, Cariou A, et al. European Resuscitation Council and European Society of Intensive Care Medicine Guidelines for Post-resuscitation Care 2015: Section 5 of the European Resuscitation Council Guidelines for Resuscitation 2015. Resuscitation. 2015;95:202-22. https://doi.org/10.1016/j.resuscitat ion.2015.07.018.

11. Barr J, Fraser GL, Puntillo K, et al. Clinical practice guidelines for the management of pain, agitation, and delirium in adult patients in the intensive care unit. Crit Care Med. 2013;41(1):263-306. https://doi.org/10.1097/CCM.0b013e3182783b72.

12. Cormio M, Robertson CS. Ultrasound is reliable method for determining jugular bulb dominance. J Neurosurg Anesthesiol. 2001;13(3):250-4. https://doi.org/10.1097/00008506-20010700000014.

13. Bhardwaj A, Bhagat H, Grover VK. Jugular venous oximetry. J Neuroanaesthesiol Crit Care. 2015;2:225-31. https://doi. org/10.4103/2348-0548.165046.

14. Brain Resuscitation Clinical Trial I Study Group. A randomized clinical study of cardiopulmonary-cerebral resuscitation: design, methods, and patient characteristics. Am J Emerg Med. 1986;4:72-86.

15. Robertson C. Desaturation episodes after severe head injury: influence on outcome. Acta Neurochir Suppl (Wien). 1993;59:98-101. https://doi.org/10.1007/978-3-7091-9302-0_17.

16. Robertson CS, Gopinath SP, Goodman JC, Contant CF, Valadka $\mathrm{AB}$, Narayan RK. $\mathrm{SjvO}_{2}$ monitoring in head-injured patients.
J Neurotrauma. 1995;12(5):891-6. https://doi.org/10.1089/ neu.1995.12.891.

17. Le Roux P, Menon DK, Citerio G, et al. Consensus Summary Statement of the International Multidisciplinary Consensus Conference on Multimodality Monitoring in Neurocritical Care. Intensive Care Med. 2014;40(9):1189-209. https://doi.org/10.1007/ s00134-014-3369-6 (Epub 20 Aug 2014).

18. Chaikittisilpa N, Vavilala MS, Lele AV. Jugular venous oximetry. In: Prabhakar H, editor. Neuromonitoring techniques. 1st ed. London: Elsevier, Academic; 2017. p. 57-75.

19. Wallin E, Larsson IM, Nordmark-Grass J, et al. Characteristics of jugular bulb oxygen saturation in patients after cardiac arrest: a prospective study. Acta Anaesthesiol Scand. 2018;62(9):1237-45. https://doi.org/10.1111/aas.13162.

20. Sekhon MS, Gooderham P, Menon DK, et al. The burden of brain hypoxia and optimal mean arterial pressure in patients with hypoxic ischemic brain injury after cardiac arrest. Crit Care Med. 2019;47(7):960-9. https://doi.org/10.1097/CCM.0000000000 003745 .

21. Sunde K, Pytte M, Jacobsen D, Mangschau A, Jensen LP, Smedsrud C, Draegni T, Steen PA. Implementation of a standardised treatment protocol for post resuscitation care after out-of-hospital cardiac arrest. Resuscitation. 2007;73(1):29-39. https://doi. org/10.1016/j.resuscitation.2006.08.016.

22. Gaieski DF, Band RA, Abella BS, et al. Early goal-directed hemodynamic optimization combined with therapeutic hypothermia in comatose survivors of out-of-hospital cardiac arrest. Resuscitation. 2009;80(4):418-24. https://doi.org/10.1016/j.resuscitat ion.2008.12.015.

23. Chamorro C, Borrallo JM, Romera MA, Silva JA, Balandín B. Anesthesia and analgesia protocol during therapeutic hypothermia after cardiac arrest: a systematic review. Anesth Analg. 2010;110(5):1328-35. https://doi.org/10.1213/ANE.0b013e3181 d8cacf.

24. Michenfelder JD, Theye RA. Cerebral protection by thiopental during hypoxia. Anesthesiology. 1973;39(5):510-7. https://doi. org/10.1097/00000542-197311000-00010.

25. Grady R. Cerebral protection. In: Faust's anesthesiology review E-book. 4th ed. Philadelphia: Elsevier Saunders; 2014. p 307-9.

26. Adembri C, Venturi L, Pellegrini-Giampietro DE. Neuroprotective effects of propofol in acute cerebral injury. CNS Drug Rev. 2007;13(3):333-51. https://doi.org/10.111 1/j.1527-3458.2007.00015.x.

27. Urwin SC, Menon DK. Comparative tolerability of sedative agents in head-injured adults. Drug Saf. 2004;27(2):107-33. https://doi. org/10.2165/00002018-200427020-00003.

28. Brophy GM, Bell R, Claassen J, et al. Neurocritical Care Society Status Epilepticus Guideline Writing Committee. Guidelines for the evaluation and management of status epilepticus. Neurocrit Care. 2012;17(1):3-23. https://doi.org/10.1007/s1202 8-012-9695-z.

29. Oddo M, Crippa IA, Mehta S, et al. Crit Care. 2016;20:128. https ://doi.org/10.1186/s13054-016-1294-5.

30. Kim SH, Choi SP, Park KN, et al. Early brain computed tomography findings are associated with outcome in patients treated with therapeutic hypothermia after out of hospital cardiac arrest. Scand J Trauma Resusc Emerg Med. 2013;21:57. https://doi. org/10.1186/1757-7241-21-57.

31. Youn CS, Park KN, Kim JY, et al. Repeated diffusion weighted imaging in comatose cardiac arrest patients with therapeutic hypothermia. Resuscitation. 2015;96:1-8. https://doi.org/10.1016/j. resuscitation.2015.06.029.

32. Langkjær S, Hassager C, Kjaergaard J, et al. Prognostic value of reduced discrimination and oedema on cerebral computed tomography in a daily clinical cohort of out-of-hospital cardiac arrest 
patients. Resuscitation. 2015;92:141-7. https://doi.org/10.1016/j. resuscitation.2015.03.023.

33. Menon DK, Coles JP, Gupta AK, et al. Diffusion limited oxygen delivery following head injury. Crit Care Med. 2004;32(6):138490. https://doi.org/10.1097/01.ccm.0000127777.16609.08.

34. Hoedemaekers CW, Ainslie PN, Hinssen S, et al. Low cerebral blood flow after cardiac arrest is not associated with anaerobic cerebral metabolism. Resuscitation. 2017;120:45-50. https://doi. org/10.1016/j.resuscitation.2017.08.218.

35. Lemiale V, Huet $\mathrm{O}$, Vigué $\mathrm{B}$, et al. Changes in cerebral blood flow and oxygen extraction during post-resuscitation syndrome. Resuscitation. 2008;76(1):17-24. https://doi.org/10.1016/j.resus citation.2007.06.028.
36. Hayman EG, Patel AK, Kimberly WT, Sheth KN, Simard JM. Cerebral edema after cardiopulmonary resuscitation: therapeutic target following cardiac arrest? Neurocrit Care. 2018;28(3):27687. https://doi.org/10.1007/s12028-017-0474-8.

37. Tameem A, Krovvidi H. Cerebral physiology. BJA Educ. 2013;13:113-8. https://doi.org/10.1093/bjaceaccp/mkt001.

Publisher's Note Springer Nature remains neutral with regard to jurisdictional claims in published maps and institutional affiliations. 